\title{
Observation on the Expression of Regional Culture in Packaging Design
}

\author{
Ming Li* \\ Department of Visual Communication, Guangzhou Huashang College, Zengcheng 511300, China \\ *Corresponding author: Ming Li, louman123123@163.com
}

\begin{abstract}
At present, regional culture has become the preference for many modern local brand packaging to accentuate design elements. This paper briefly introduces the concept of regional culture, linking it with Pu'er tea packaging designs, analyzes and probes into the value and significance of regional culture expression in packaging designs.
\end{abstract}

Keywords: Packaging design; Regional culture; Value expression

Publication date: June 2021; Online publication: June 30, 2021

\section{Introduction}

China's economic development in various regions is imbalanced. Their customs, cultural habits, and consumption are different which often affect their lifestyle. At present, the manifestations of local culture in packaging designs are more evident than before. The integration of creative cultural expressions into brand packaging has laid the foundation for the development of the local culture and jointly established the brand image and values. The methods to highlight brand packaging designs have become an issue for designers to weigh thoroughly. The historical development, accumulation of all kinds of local culture, traditional folk customs, and spiritual connotations have affected the local brands which gradually established independent styles and became unique cultural heritages. Regional culture has become the preference for many modern local brand packaging to accentuate design elements. Scholars viewed it from different angles. For example, Lu Fei pointed out that local cultural factors linked consumers and producers via their packaging designs. ${ }^{[1]}$ By integrating local cultural elements into packaging designs, consumers may reinforce their understanding toward a product and eventually, increase their purchasing desires. There are various national cultural resources in different local cultures. The rational use of regional culture in packaging designs provides an opportunity to promote industrial development and growth of the local economy. Wang Shuhui stated that through the research and development of Suzhou landscaping rules and visual language, graphic designs, as well as packaging, a creative cultural packaging design for Biluochun tea was created which manifested the cultural charm of Suzhou. ${ }^{[2]}$ Efforts should be made to emphasize the importance and protection of local cultures in order to create higher cultural values in the creative market. Wang Anton applied practical significance to brand packaging designs through the local culture. In his case study, he explained the cultural connotations and sentiments manifested in packaging designs which reflected the brand uniqueness and excellence of local brand packaging designs. ${ }^{[3]}$

\section{The Concept of Regional Culture}

Regional culture refers to the culture that spreads in a specific area which affects the behavior and habits of the local people. It is a characteristic culture that integrates folk customs and other civilizations into the environment of a specific area. After their integration, they form a unique culture with a local brand. The 
cultural characteristics of a specific region are unique, and they are deeply imprinted in the local culture. Their originality distinguishes them from the cultural characteristics of other regions. Local culture has local characteristics which are passed down from generation to generation. It does not only reflect the customs and characteristics of the region, but also, the living conditions of its' residents and the historical relics. Cultural forms, social customs, and lifestyle directly affect the values and behaviors of local people. Local culture is not formed overnight, but through a long historical process. The regional characteristics of each local culture are obvious as there are great differences due to different cultural forms. However, due to similarities between regions, the concept of "region" cannot be based on geography, but it should be seen in the perspective of humanity and society. The regional concept constitutes of humans and historical spaces based on natural geographical areas. Under the influence of a region, collective characteristics of local culture is formed, and similar regions would have similar characteristics. The sustainable development of local culture does not only depend on its outstanding civilization heritages but also integrates the excellent achievements of other cultures. The level of urban modernization and social civilization determines peoples' tolerance towards different cultures. With economic globalization, the acceptance and merging of different cultures to form regional culture have begun. This process of acceptance and integration demarcates the cultural inheritance and development. In facing the development of cultural consumption, the concept of "keeping pace with changing times" should be embraced.

\section{Regional Culture Expression in Packaging Design}

The graphic art in tea packaging designs allows consumers to gain more information about tea products, as well as to appreciate their functional and cultural values. An excellent graphic packaging design will be able to solve space constraints and increase the product's attractiveness. This paper uses Yunnan Pu'er tea as an example. Dai, Bulang, Lahu, Jinuo, Hani and other ethnic minorities have a long history of tea cultivation. In the long run of tea consumption, they had formed unique tea cultures. The inspiration of Pu'er tea design came from totemism. In ancient times, people believed that hunting, planting, and other production activities needed the protection of their ancestors or gods. The packaging design of Pu' er tea is based on ethnic minorities which comprises of ethnic symbols and mascots (elephants and peacocks were regarded as mascots by the Dai people). National art elements in clothes and paintings provided reference and ideas for the packaging design of Pu'er tea. They are full of Yunnan's regional colors and national style. Therefore, in the packaging design of Pu'er tea, the cultural history, brand influence, and regional characteristics should be fully displayed. ${ }^{[4]}$ It should not only display the national characteristics of the region, but also the historical and cultural heritages of tea culture while revealing the cultural connotations of the tea itself. Therefore, the Yunnan Pu'er tea packaging needs to maximize the vibrancy of the tea by emphasizing the use of graphic designs to promote it. Yunnan's national culture is based on the origin of tea. The local tea garden style and regional characteristics are shown via photographs. The following figures are the packaging designs of Pu'er tea (Figure 1).

\section{Expression of Regional Cultural Value in Packaging Designs}

In the development of the economy, the value of expressing regional culture in packaging designs should not be underestimated. This paper discusses three aspects which are the cultural value, commercial value, and aesthetic value. 

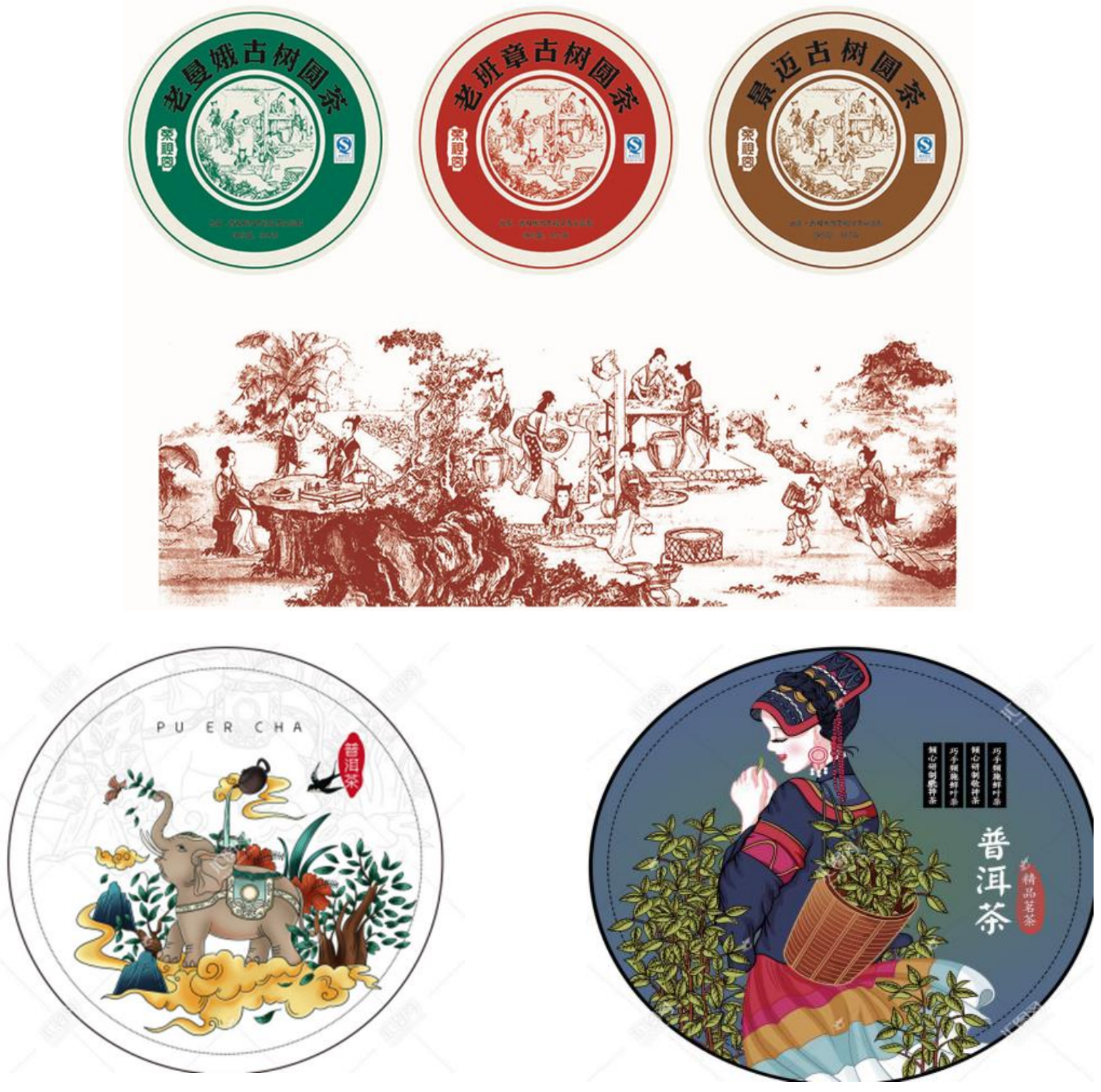

Figure 1. Packaging designs of Pu'er tea

\subsection{Cultural value}

In today's multiculturalism and integration, many local cultural elements are used in products' packaging designs. For example, adding mascots as designs to tea packaging would not only strengthen the promotion of these products but also, expand their regional characteristics. While these designs are firmly established in the public, local cultures or customs will be revived.

\subsection{Commercial value}

The basic purpose of packaging is to attract the consumers' attention to boost consumption. In many products, the actual value of the products is not very different; however, it is the packaging designs which would make a product stand out. In regard to that, even with high prices, the consumers' preference for a 
certain product would not be affected. The unique charm is in the combination with packaging designs of geographical elements.

\subsection{Aesthetic value}

Modern regional packaging designs have broken traditions and changed the traditional style. In the eyes of people, lively and innovative regional packaging designs have become new trends. They have replaced the previous complex and inelegant designs with simpler, lighter, brighter, and liberal styles. All successful local packaging designs have their own beauty. The fundamental purpose of these designs is for people to appreciate the beauty and aesthetics of certain products as well as to emphasize their practicality. It enriches the public's aesthetic taste and achieves the purpose of attracting and increasing consumption.

\section{Significance of Regional Culture Expression in Packaging Designs}

\subsection{Integrating local culture into packaging designs to create value}

Packaging has become an indispensable carrier to display the functions and value of a certain product. The development of packaging industry promotes the comprehensive use and development of local packaging designs. Brand packaging integrates the local culture, historical, and spiritual significance. Each region has its own unique historical, cultural, geographical characteristics, and symbols. Designers need to consider the cultural aspects of a specific area, ahead of the production process and comprehensively analyze them. For example, the local history of a certain area would entail its cultural features such as national customs, folktales, and legends which could be used as packaging design elements. Based on the analysis and understanding of the local culture and history of specific areas, common expression forms of packaging designs are then selected to express the local characteristics to the greatest extent, so that the audiences would be able to fully appreciate the local culture and increase consumption of a certain product, thereby, benefiting both economic and cultural factors.

\subsection{Dismantling and reconstructing regional cultural symbols}

Dismantling and reconstruction are practical methods which are usually reflected in modern packaging designs. They are integrated with various basic forms of designs in combination of charming structures and scenes as well as rich connotations in packaging design products. Dismantling does not mean destruction but it illustrates a system whereby new forms of beauty combining with folk art can be constructed for packaging designs. Folk art images reflect local cultural connotations. At present, it is necessary to explore auspicious meanings and conceive ideological innovations when using mascots as designs in certain packaging. The dismantling and reconstruction of regional cultural symbols enrich the style of packaging designs and promote the spread of regional culture.

\subsection{Inheritance and development of traditional folk crafts}

Material and spiritual artifacts are the two main aspects in culture which complement one other. Spiritual culture determines material culture. Folk handicrafts are not only important carriers of local traditional culture, but also cultural heritages. Therefore, folk handicrafts also influence the characteristics of the national material culture. There are two forms of inheritance and development of folk crafts. The first is the act of inheriting whereby the form and content of traditional crafts are inherited by using traditional creative ideas and techniques. In packaging designs, the integration of regional culture with modern aesthetics and functional skills then provides opportunities to innovate and regenerate designs. This does not only involve the inheritance of folk crafts, but also increases the sales of products. 


\subsection{Combination of local culture and modern-day designs}

Packaging designs have been infused with cultural patterns for a long time. Design culture exists and develops in specific fields, showing different artistic styles and aesthetic characteristics at different stages of time. With the gradual collapse of the traditional design culture yet inadequate establishment of the new design culture, there is a need to clarify the relationship between tradition and modernism, between the East and the West, as well as to examine this context with a fresh perspective and attitude. ${ }^{[5]}$ Packaging designs have been emphasizing the characteristics of regional culture; hence, regional characteristic packaging designs have become the main development factor. However, it is also necessary to consider the elements of modern packaging designs for overall development. By introducing local folk art forms and local culture into modern-day packaging designs and modern-day designs respectively, the connection between product designs and regional cultures would be emphasized.

\section{Conclusion}

Regional culture has become the preference for many modern local brand packaging to accentuate design elements. The integration of creative cultural expression into brand packaging has laid the foundation for the development of local culture as well as establishing the image and value of a brand. Designers should focus on the methods to highlight the excellence of brand packaging designs. The long historical development, accumulation of all kinds of local cultures, traditional folk customs, and spiritual connotations have affected the local brand, which gradually developed into independent styles and became unique cultural heritages. In addition to the discussion of Pu'er tea packaging designs, this paper also introduced the concept of regional culture and analyzed the value and significance of regional culture expression in packaging designs in order to promote the integration of regional culture in packaging designs.

\section{Funding}

Supported by Huashang College project (HS2018CXQX23), the provincial and university-level coconstruction project (undergraduate teaching quality and teaching reform project, construction project), college students off-campus practice teaching base construction project.

\section{Disclosure statement}

The author declares no conflict of interest.

\section{References}

[1] Lu F, Wen P, 2021, On the expression of regional culture in packaging design. Textile Industry and Technology, 50(2): 99-100.

[2] Wang SH, Cheng ZX, Yu Q, et al., 2021, Analysis on packaging design of cultural and creative products of "Suyuan love talk" - visual abstraction and expression of regional culture. Green Packaging, (2): $65-9$.

[3] Wang AT, 2021, Research on the application of regional cultural elements in packaging design. Hunan Packaging, 36(1): 40-2.

[4] Bai Y, 2013, Research on the application of regional cultural characteristics in the packaging design of Pu'er tea. Kunming University of Science and Technology.

[5] Hu L, Yao A, Yue X, 2021, The application of local cultural symbols in the packaging design of local products - taking Guangdong characteristic packaging as an example. Green Packaging, (3): 74-6. 